
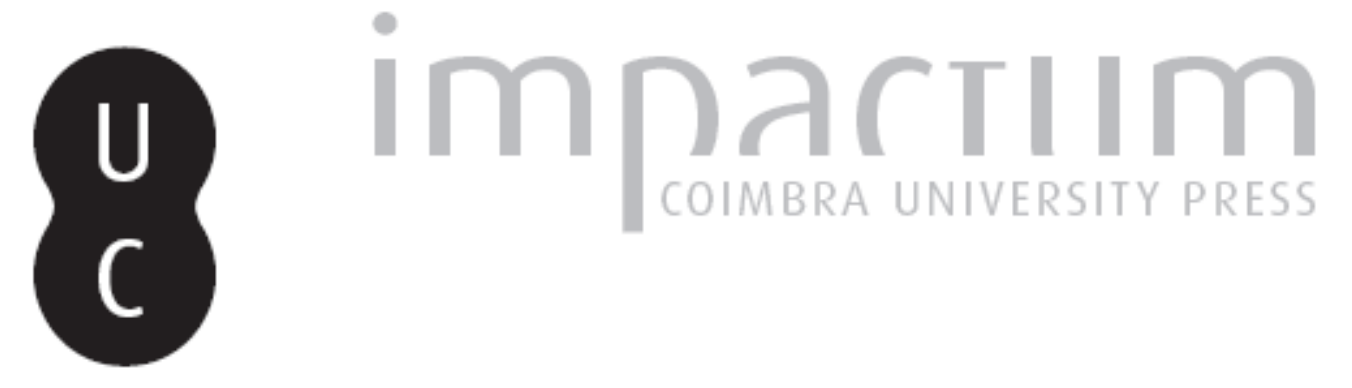

Ville e villini: casas de arquitectos italianos no Portugal de Oitocentos

Autor(es): $\quad$ Ferreira, Teresa Cunha

Publicado por: Imprensa da Universidade de Coimbra

URL persistente:

URI:http://hdl.handle.net/10316.2/44978

DOI:

DOI:https://doi.org/10.14195/0870-8584_12_15

Accessed : $\quad$ 26-Apr-2023 15:33:29

A navegação consulta e descarregamento dos títulos inseridos nas Bibliotecas Digitais UC Digitalis, UC Pombalina e UC Impactum, pressupõem a aceitação plena e sem reservas dos Termos e Condições de Uso destas Bibliotecas Digitais, disponíveis em https://digitalis.uc.pt/pt-pt/termos.

Conforme exposto nos referidos Termos e Condições de Uso, o descarregamento de títulos de acesso restrito requer uma licença válida de autorização devendo o utilizador aceder ao(s) documento(s) a partir de um endereço de IP da instituição detentora da supramencionada licença.

Ao utilizador é apenas permitido o descarregamento para uso pessoal, pelo que o emprego do(s) título(s) descarregado(s) para outro fim, designadamente comercial, carece de autorização do respetivo autor ou editor da obra.

Na medida em que todas as obras da UC Digitalis se encontram protegidas pelo Código do Direito de Autor e Direitos Conexos e demais legislação aplicável, toda a cópia, parcial ou total, deste documento, nos casos em que é legalmente admitida, deverá conter ou fazer-se acompanhar por este aviso. 


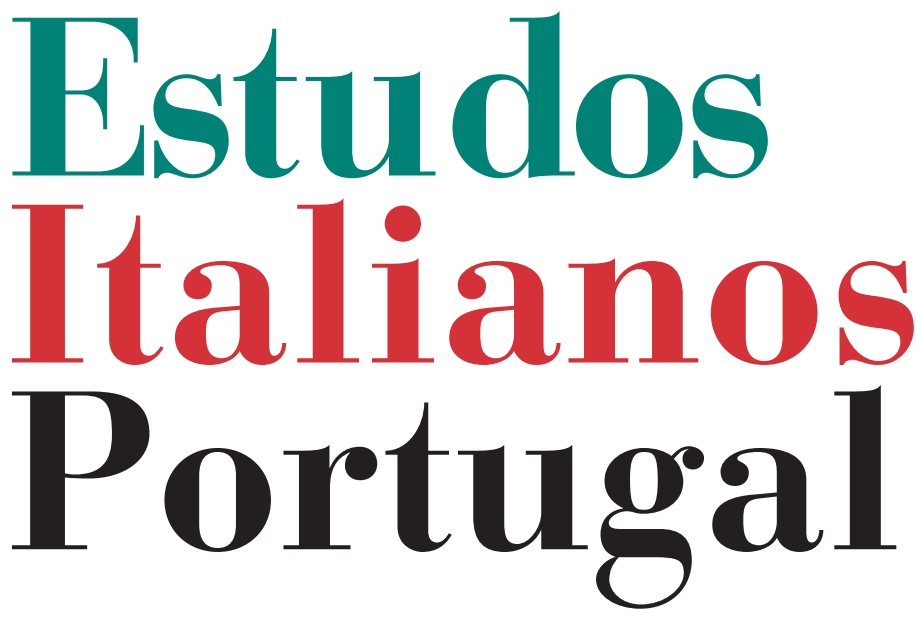

Instituto

Italiano

de Cultura

de Lisboa

Nova Série

No 12

2017 


\title{
VILLE E VILLINI. CASAS DE ARQUITECTOS ITALIANOS NO PORTUGAL DE OITOCENTOS
}

\author{
Teresa Cunha Ferreira*
}

\section{INTRODUÇĀO}

O SÉCUlO XIX É MARCADO pela presença de numerosos artistas e arquitectos italianos em Portugal. Este não é um fenómeno isolado, já que a cultura artística portuguesa é historicamente pontuada pelas relaçōes com a Península Itálica, intensificadas entre os séculos XVI e XVIII, com a transferência de numerosos engenheiros militares, arquitectos e artistas italianos, para trabalhar nas colónias e na renovação urbana, arquitectónica e artística do país.

A estabilidade política e a prosperidade económica das primeiras décadas do século XVIII atrai artistas italianos para a corte de D. João V (r. 1706-1750), que convida Filippo Juvarra (1678- 1736) para projectar um novo complexo monumental junto ao rio (a poente da cidade), à imagem de uma capital de império que pretendia rivalizar com Roma ${ }^{1}$. Deste período, data também a Capela de $S$. João

* Licenciatura em Arquitectura pela Faculdade de Arquitectura da Universidade do Porto (FAUP) e Doutoramento Europeu no Politécnico de Milão (em co-tutela com a FAUP). Professora convidada no Programa Doutoral da FAUP, membro do Centro de Estudos em Arquitectura e Urbanismo (CEAU-FAUP) e membro do Conselho de Administração do ICOMOS-Portugal. tferreira@arq.up.pt

${ }^{1} \mathrm{D}$. João $\mathrm{V}$ teria pedido a Juvarra "che facesse un disegno del palazzo reale, della chiesa patriarcale, del palazzo per il patriarca e della canonica, con questa injunzione che quella fabbrica dopo la rinomata mole di S. Pietro di Roma, tenesse il primo posto". Cfr. Rossa, W., A imagem ribeirinha de Lisboa in A urbe e o traço: uma década de estudos sobre o urbanismo português, Coimbra: Almedina, 2002, p. 105. 
Baptista ${ }^{2}$, obra arquitectónica e escultórica projectada entre 1742-1750 pelos arquitectos Luigi Vanvitelli (1700 - 1773) e Nicola Salvi (1697 - 1751), sendo posteriormente transportada e montada no local de destino, a Igreja de S. Roque em Lisboa.

Já no reinado seguinte (D. José r. 1750-1777) o cenógrafo bolonhês Giovanni Carlo Sicinio Galli Bibiena ${ }^{3}$ (1717 -1760) é contratado para dirigir a construção do Teatro da Ópera do Tejo, inaugurado em 1753, desempenhando um importante papel na introdução e desenvolvimento da arte cenográfica em Portugal.

Na segunda metade do século XVIII e no início do século XIX identificam-se vários artistas e arquitectos italianos a trabalhar em Portugal ${ }^{4}$, alguns dos quais viriam a adquirir a nacionalidade portuguesa. Grande parte desses artistas co-

${ }^{2}$ Cfr. Vale, T. (coord.), A Capela de São João Batista da Igreja de São Roque. A Encomenda, A Obra, As Coleçôes, Lisboa: Imprensa Nacional-Casa da Moeda/Santa Casa da Misericórdia de Lisboa, 2015; Vale T. (coord.), De Roma para Lisboa: Um Álbum para o rei Magnânimo, Roteiro da exposição, Lisboa: SCRIBE/Santa Casa da Misericórdia de Lisboa, 2015.

${ }^{3}$ Giovanni Carlo Sicinio Galli Bibiena (Bolonha, 1717 - Lisboa, 1760) é descendente de uma família de arquitectos e cenógrafos, originários de Bolonha, que desenvolvem a pintura de "trompe l'oeil" e que se estabelecem nas mais importantes cortes europeias. Em Lisboa, para além do teatro da corte destruído no terramoto de 1755, realiza a Real Barraca (residência real em madeira instalada na encosta da Ajuda na sequência do terramoto), projecta a Igreja da Memória e é nomeado arquitecto das obras nos Palácios Reais. Cfr. Gallingani, D., I Bibiena: una famiglia in scena: da Bologna all'Europa, Florença: Alinea, 2002, pp. 31-32; Pereira, P., Dicionario da Arte Barroca em Portugal, Lisboa, Presença, 1989, pp. 86-88.

${ }^{4}$ Em 1760 encontravam-se registados artistas como Nicolau Apolloni, Francisco Assiza, Carlos Baldi, Maximino Bernabei, Alexandre Berthocelini, Valerio Bertozzi, Luigi Bistorini, João S. Ciuci, João B. Coccoli, Francisco X, Constanzi, Felippe Conti, Nicolao Conti, Claudio Dorelli, Sinibaldo Dorelli, Domingos Federici, Oracio Federici, Pedro Fomentin, Angelo M. Gallini, Jose Maruzzi, Petronio Mazzoni, João A. Penacchini, Crispim Profile, Francisco Pocagari, Serafin Seri. Ver Chancellaria de D. José, liv. 48, Torre do Tombo, cit. por Francisco de Sousa Viterbo, Dicionário histórico e documental dos arquitectos, engenheiros e construtores portugueses, Lisboa, Imprensa Nacional - Casa da Moeda, 1988, 3 vols. [reed. facsimilada ed. 1922]. 
meça a trabalhar como cenógrafo ${ }^{5}$, mas acaba por desenvolver actividade noutras áreas como a arquitectura e decoração de interiores. É o caso de Fortunato Lodi' ${ }^{6}$ (1805-1883), Giuseppe Cinatti (1808-1879), Achille Rambois (1810-1882) e Luigi Manini (1848-1936).

Importa, no entanto, deixar uma nota sobre o panorama de crise política que se vive no início do século XIX, designadamente com as invasões francesas (1807-1811), a transferência da corte portuguesa para o Brasil (1808-1822) e a guerra civil (1828-1834), o que tem consequências drásticas em todas as estruturas públicas, incluindo as instituições de ensino artístico. Este contexto reflecte-se no percurso formativo dos arquitectos (integrado nas Academias de Belas Artes), que então carecia de bases técnicas e de uma reforma profunda, factor que, entre outros aspectos, determinou a sorte dos estrangeiros - com predominância de italianos e

${ }^{5}$ Entre os cenógrafos italianos que trabalham em Portugal evidenciam-se os nomes de Teodoro Albinola, Giacomo Azzolini, Antonio Baila, Teodoro Bianchi, Giovani Chiari, Luigi Chiari, Giuseppe Cinatti, Roberto Clerici, Salvatore Colonnelli, Angelo Ferri, Vicenzo Gabelli, Ercoli Lambertini, Luigi Manini, Vicenzo Mazzoneschi, Petronio Mazzoni, Francesco Mignola, Achille Rambois, Giovani Ricardi, Samarini, Giovanni Nicolo Sernandoni, Domenico Schiopetta, Antonio Stopani, Rafaello Trapani (ib.).

${ }^{6}$ Fortunato Lodi (1805-1883), natural de Bolonha, onde completa com distinção os estudos na Academia de Belas Artes, vem para Portugal em 1826 por intermédio do seu tio F. A. Lodi, empresário e cenógrafo do Teatro São Carlos. Lodi trabalha para o Conde de Farrobo, seu mecenas entre 1834 e 1848, para quem realiza a reedificação do Teatro Thalia situado na Quinta das Laranjeiras. A sua obra principal é o Teatro D. Maria II inaugurado em 1846, que lhe valeu a nomeação como arquitecto da Casa Real. Realiza o Palácio da Quinta das Águias e, em 1848 regressa a Itália onde desenvolve actividade de ensino e arquitectura, primeiro em Bologna e Bergamo, regressando finalmente a Bolonha, onde se dedica ao ensino na cátedra de Arquitectura e publica vários manuais didácticos, exercendo também actividade de arquitecto e decorador de igrejas, palácios, teatros e da estação ferroviária de Bolonha. Ver http:// www.casaruibarbosa.gov.br/acasasenhorial/index.php/artistas/48-artistas/546-fortunato-lodi-1812-1882 (consultado a 15-05-2017). 
franceses $^{7}$ - que, neste período, foram os principais actores da renovação urbanística e arquitectónica da capital.

No contexto das relações artísticas entre Itália e Portugal no século XIX, é também de sublinhar o papel dos monarcas no mecenato e na intensificação do gosto pela ópera e pelo teatro em Portugal, em particular do príncipe consorte D. Fernando Saxe-Coburgo-Gotha $(1816-1885)^{8}$ - casado com D. Maria II (1819-1853) e em segundas núpcias com a cantora de ópera Elise Hensler (1836-1929) - e o do seu descendente, o rei D. Luís I (1838-1889), e de sua mulher, D. Maria Pia de Sabóia (1847-1911). Este casamento, ocorrido em 1862, representa um importante momento na história das relações entre as duas nações.

Já no terceiro quartel do século XIX, uma segunda leva de artistas estrangeiros viria para Portugal ensinar desenho nas novas Escolas Industriais, instituídas pela reforma de $1880^{9}$, entre os quais Cesare Ianz (?-1901) ${ }^{10}$, Nicola Bigaglia (1841-1908) e o suíço Ernesto Korrodi (1870-1944).

${ }^{7}$ Entre estes P. J. Pezerat, J. Colson, A. Rambois e G. Cinatti e, numa segunda geração, L. Manini, H. Lusseau, N. Bigaglia, S. G. Locati, entre outros. Sobre o tema ver, além do mais, José-Augusto França, $A$ arte em Portugal no século XIX, Venda Nova, Bertrand, 1974, 2 vols.

${ }^{8}$ De origem alemã, parente de importantes casas reais europeias, era um homem culto, cosmopolita, coleccionador de arte e antiguidades. Foi mecenas de restauros nos mosteiros dos Jerónimos, da Batalha e de Alcobaça, tendo também conduzido a concepção do Palácio e Parque da Pena em Sintra. Para aprofundamento ver J. Teixeira, $D$. Fernando II: rei-artista: artista-rei, Lisboa, Fundação da Casa de Bragança, 1986; Romantismo. Figuras e factos da época de D. Fernando II, Sintra, Instituto de Sintra, 1888.

${ }^{9}$ L. V. Costa, Ernesto Korrodi. 1889-1944. Arquitectura, Ensino e Restauro do Património, Lisboa, Estampa, 1997.

${ }^{10}$ Arquitecto italiano de origem austríaca, foi um dos técnicos que chegou a Portugal em 1888 para ensinar desenho no ensino industrial, tendo realizado também projectos de arquitectura, entre os quais a fachada do edifício do Coliseu de Lisboa (ca. 1890), do Edifício dos Paços do Concelho da Figueira da Foz (1894-1897, com Giuseppe Fiorentini), a reconstrução do Forte de Santa Cruz no Estoril (1900) e uma casa na Rua Júlio de Andrade em Lisboa, junto às casas projectadas por Sebastiano Locati para a família Andrade. Ver, entre outros, J. Pedreirinho, Dicionário dos arquitectos activos em Portugal do séc. I à actualidade, Porto, Afrontamento, 1994, p. 34. 
Analisando a obra de arquitectos italianos no Portugal de Oitocentos, identificam-se ainda outros casos mais isolados, como Sebastiano Giuseppe Locati (1861-1939) que veio trabalhar em Lisboa por intermédio de Alfredo de Andrade (1839-1915), pintor e arquitecto luso-italiano que, desempenha um importante papel nas relações entre Itália e Portugal no século XIX. Considere-se, por um lado, o âmbito da renovação do ensino artístico - contributos para projectos de reforma da Academia de Belas Artes de Lisboa, encomenda de livros, gessos e outros materiais didáticos vindos de Itália ${ }^{11}$ -, e por outro lado, a participação directa ou indirecta em projectos e obras de arquitectos italianos em Portugal que apresentamos neste artigo.

\section{VILLE E VILLINI}

O projecto da habitação é sem dúvida a principal fonte de encomenda dos arquitectos italianos no Portugal de Oitocentos, como resposta quer ao crescimento e transformação das cidades, quer às expectativas de uma burguesia empenhada na sua afirmação social.

Entre os modelos italianizantes mais apreciados na época, destacam-se o palacete de maiores dimensóes, geralmente com inspiração neo-renascentista (villa) e a casa de menores dimensões, frequentemente com maior articulação volumétrica e com maior difusão em áreas suburbanas ou locais de vilegiatura (villino). Destes modelos derivam a "villa com torre" e o "villino a castello" 12 , este último amplamente disseminado nas periferias das cidades e nos locais de vilegiatura

${ }^{11}$ Para aprofundamento ver L. V. Costa, Alfredo de Andrade. 1839-1915. Da pintura à invenção do património, Lisboa, Vega, 1997; T. Ferreira, Il Portogallo di Alfredo de Andrade. Città, architettura, património, Santargangelo di Romagna, Maggioli, 2014; Arquivo Privado da Família Andrade (APFA).

${ }^{12}$ Ver, entre outros, M. V. Davico; E. Dellapiana (coord.), Dal castrum al castello residenziale. Il Medioevo del reintegro o dell'invenzione, Torino, CELID, 2000. 
em Itália, principalmente a partir do terceiro quartel do século XIX. Como refere R. Carlucci, "Ogni famiglia oggi vuole una dimora agiata e ben costruita [...]. Piace soprattutto il villino e in alcune città già si vedono sorgere, alla periferia, specialmente, gruppi di villini, quasi tutti piccini e civettuoli, che sono, nel medesimo tempo, rifugio di pace, fonte di soddisfazione" 13 .

Este fenómeno decorre da assimilação de um gosto inspirado na estética anglo-saxónica do pitoresco ${ }^{14}$ que incentiva uma distribuição livre e assimétrica dos volumes, admitindo a coexistência de diferentes estilos e a introdução de dispositivos como bow-window, logge e torres frequentemente acasteladas. Importa também referir o incremento da circulação de publicações - que podem dividir-se genericamente em dois tipos, os manuais ou guias do construtor e os repertórios de modelos ${ }^{15}$-, as quais fornecem as bases prático-aplicativas para uma grande diversidade de soluções formais e construtivas.

Em suma, a casa torna-se um campo prioritário de reflexão e experimentação por parte dos arquitectos, como sublinha também Camillo Boito: "In una società democratica, quale è la nostra, il monumento essenziale, il contenente, per così

${ }^{13}$ R. Carlucci, Il villino italiano. Progetti completi con piante in scala metrica dei migliori ingegneri ed architetti moderni, Torino, Lartista moderno, 1930, 2. ${ }^{\mathrm{a}}$ ed., vol. 1, p. VII.

${ }_{14}$ Ver, entre outros, H. R. Hitchcock (coord.), "The development of the detached house in England and America from 1800 to 1900", in Architecture. Nineteenth and twentieth centuries, Hardmondsworth, Penguin, 1958, pp. 253-280.

${ }^{15}$ Ver, entre outros, V. Cicala, Ville e castelli d'Italia. Piemonte e Liguria, Milano, E. Bernardi e C. ${ }^{a}$, Industria delle Arti Grafíche, 1911; C. Bianchi, Le ville moderne in Italia. Ville del Lago di Como e della Lombardia: facciate, particolari, sezioni, piante, Torino, Crudo \& C, s. d.; Ville e villette moderne. Progetti e schizzi di facciate e piante, Torino, Crudo \& C., s. d.; Il villino moderno. Raccolta di progetti di ville e villini, Milano, G. Martinenghi \& F.lli, s. d.; Ville e villini. Raccolte di progetti e vedute di lavori eseguiti, Piacenza, Casa editrice libraria C. \& C, Tarantola, s. d.; T. Antonicelli; C. Leonardi; G. Martinenghi et al., Ville e casette. Raccolta di 80 progetti, Milano, U. Hoepli, 1915. 
dire, del mondo architettonico, deve essere la casa. I greci avevano i loro templi, i loro propilei; i romani i loro anfiteatri, le loro terme; i primi cristiani le loro catacombe, le loro basiliche; gli uomini vestiti di ferro le loro cattedrali, i loro palazzi del comune e via via: noi abbiamo la nostra abitazione"16.

\section{VILLINo D’ALmEIDA No ESTORIL}

"Castello, uma casa acomodada no conforto e na vida da actualidade" 17 são as premissas indicadas por Carlos Maria Eugénio de Almeida (1845-1914) a Alfredo de Andrade, ao mesmo tempo que pedia a referência de "um homem competente italiano" para projectar a sua "casa de campo" no Monte Estoril. Não é de estranhar a preferência por um arquitecto italiano, visto que os Eugénio de Almeida tinham já encomendado vários projectos a Giuseppe Cinatti $(1808-1879)^{18}$ - arquitecto-cenógrafo, que desenvolve numerosos projectos de arquitectura, restauro e jardins, muitos dos quais em parceria com Achille Rambois (c. 1810-1880) ${ }^{19}$ - e assim garan-

${ }^{16}$ C. Boito, Architettura del Medio Evo in Italia. Con una introduzione sullo stile futuro dell'architettura italiana, Milano, Ulrico Hoepli, 1880, pp. XVIII-XIX.

${ }^{17}$ Carta de C. E. Almeida a A. Andrade, 05-10-1890, Archivio di Stato di Torino (ASTo), FA, CP, B. 23.

${ }^{18}$ Nasce em Siena e estuda arquitectura na Accademia di Brera, em Milão. Por motivos políticos parte para Lyon onde inicia a actividade de cenógrafo e, em 1836, é chamado pelo empresário A. Lodi para trabalhar no Teatro de São Carlos, em Lisboa. Teve muito sucesso como arquitecto, realizando palácios, edifícios, jazigos, jardins e interiores, assim como obras de restauro, entre as quais o palácio de Calhariz, perto de Sesimbra, o Templo de Diana em Évora e as intervenções no Mosteiro dos Jerónimos, em Lisboa, cuja torre se desmoronou tragicamente em 1878. Ver M. Visentini, Dizionario biografico degli italiani, Roma, Istituto della Enciclopedia Italiana, 1981, vol. 25; J. C. Leal, Giuseppe Cinatti (1808-1879). Percurso e obra, Tese de Mestrado em História de Arte Contemporânea apresentada à FCSH da Universidade Nova, Lisboa, 1996, 2 vols.

${ }^{19}$ Nasce, estuda e trabalha em Milão, até ser convidado para o Teatro de São Carlos, em Lisboa. Com Giuseppe Cinatti, realiza um vasto número de obras em Portugal durante cerca de 42 anos. Ver J. Pedreirinho, cit., p. 186. 
tiam uma diferenciação na imagem exterior, bem como uma boa qualidade de desenho e de execução.

Como vimos, também não surpreende o modelo escolhido, villino a castello, sintetizando os princípios da vilegiatura burguesa fin de siècle: a exuberância no tratamento exterior (espelho de um status conquistado), o conforto e a adaptação às novas exigências funcionais e sociais da vida moderna ${ }^{20}$.

Alfredo de Andrade pede conselho ao amigo Camillo Boito (1836-1914) - professor na Accademia di Belle Arti de Milão e personagem central do debate arquitectónico em Itália que lhe recomenda um jovem arquitecto, Sebastiano Giuseppe Locati (1861-1936) ${ }^{21}$, o qual, apesar dos seus vinte e nove anos, já tinha projectado importantes edifícios em Milão.

Locati vai desenvolver dois projectos para o Villino D'Almeida e acompanha Andrade a Lisboa para organizar o estaleiro e ver o que seria necessário importar de Itália, para ter o Castello concluído em $1892^{22}$. É nessa ocasião que Al-

${ }^{20} \mathrm{O}$ programa previa "Cucina, office, camera servizio e 2 domestici, camera da pranzo 20 persone, 1 sala bigliardo, fumoir forse in galleria, 2 sale, 6 camere letto padronali con cameretta per toilette ognuna, 6 camere letto camarieri e servizio" e uma "scuderia per 12 cavalli e carrozziere e sellerie per 6 vetture". Além disso, segundo Andrade, "Le camere padronali dovrebbero avere una retrocamera per lavaggi e toilette". Por fim, o orçamento da casa (150 mil réis) compreenderia já 10\% dos honorários do arquitecto, que teria, em Lisboa, um arquitecto assistente.

${ }^{21}$ Estuda na Scuola Speciale di Architettura, no Istituto Tecnico Superiore de Milão e na Accademia di Brera, onde é nomeado "professore incaricato" (1887-1890), prosseguindo também carreira académica na Universidade de Pavia (1899-1935), com um breve parêntesis (1920-1921) na Regia Scuola di Architettura de Roma, onde inaugura a cadeira de Rilievo e Restauro dei Monumenti. Locati projecta edifícios de habitação, comércio e escritórios como a Casa Maddalena (1885), a Casa Carlo Sartorelli (1886-89), a Casa Consonni e a Casa Rigamonti (1887-90), assim como casas unifamiliares e, já no século seguinte, o plano geral e os principais pavilhôes da Exposição Internacional de Milão (1906). Ver, entre outros, S. G. Locati, Sebastiano Gius. Locati, architetto: progetti costruzioni rilievi, Pavia, Luigi Rossetti, 1936.; R. Bossaglia (a cura di), Archivi dal Liberty italiano. Architettura, Milano, F. Angelli, 1987, p. 579.

${ }^{22}$ Minuta de carta de A. Andrade a C. E. Almeida, in ASTo, FA, CP, B. 23 e telegrama de S. Locati a A. Andrade, in ASTo, FA, CP, B. 23. 
fredo de Andrade vai sugerir a seus irmãos a contratação do mesmo arquitecto italiano para construir as casas nos terrenos comprados no Torel, em Lisboa, já que "Elle talvez tendo mais de um trabalho ali, se quizer pode mandar vir os operários necessários para fazerem obra bôa elegante e por preço razoável. Talvez até os moveis voces poderião obter directamente da Italia, como provavelmente fará o Eugenio de Almeida"23. É curioso, assim, notar a preferência de ambos os clientes por uma solução importada, não indagando sequer sobre a possibilidade de um arquitecto local poder executar os vários projectos, o que traria vantagens práticas e económicas.

As duas propostas desenvolvidas por Locati para o Villino D'Almeida apresentam algumas semelhanças: planta quadrangular organizada em torno de um espaço central, que, no segundo projecto, ganha maior expressão, transformando-se num átrio coberto com pé direito total. As soluções diferem, porém, na articulação volumétrica: uma torre no ângulo marca a entrada, na primeira proposta, e uma bow-window saliente que se afirma exteriormente, na segunda. Relativamente ao tratamento exterior, ambos os projectos evocam um castelo neogótico marcado por "monofore polilobate, bifore, trifore, rosoni, cuspidi, guglie", isto é, "viene utilizzato tutto il repertorio decorativo del gotico con un delicato gioco cromatico che accosta alla stesura rosata del paramento murario in cotto il bianco - forse marmo - che sottolinea le partiture strutturali e gli elementi” ${ }^{24}$. Desconhecem-se, contudo, os motivos que impediram a execução do projecto de Locati para o Villino Almeida, o qual seria posteriormente adaptado para Pio Soldati, em Lugano (1911-1912) ${ }^{25}$.

${ }^{23}$ Carta de Alfredo a Júlio de Andrade, de 23-11-1890, in APFA.

${ }^{24}$ L. Erba, "II Neogotico nell'insegnamento per gli ingegneri nell'Università di Pavia a cavallo tra Ottocento e Novecento: Giuseppe Sebastiano Locati”, Rossana Bossaglia; Valerio Terraroli (a cura di), Il neogotico in Europa nel XIX e XX secolo, Milano, Maqzzotta, 1990, p. 212.

${ }^{25}$ Ver S. Locati, cit., tav. 93-95. 
Curiosamente, enquanto projectava o Villino Almeida, Locati faz um minucioso levantamento da Torre de Belém fascinado "per la bellezza scenografica" e também "perché lo stimav[a] uno dei migliori esempi di quello stile di transizione (Misto di Arabo, di Ogivale e di Rinascenza, decorante però un'ossatura sempre ogivale) che in Portogallo dicesi Manuelino" ${ }^{26}$. Os desenhos são acompanhados por uma caracterização arquitectónica da Torre "tutta quanta in pietra da taglio di un bel calcare bianco giallognolo [...] illuminata dal caldo sole dell'Estremadura, spicca d'un tono splendido sul tonno azzurro ciano del cielo" 27 .

Sebastiano Locati faria ainda um outro projecto no Estoril, desta vez para Sassetti, dono do Hotel Bragança. De escala mais modesta, esta proposta recorda os villini lombardos pela volumetria compacta com uma torre sobrelevada e beirados salientes ${ }^{28}$. Este projecto, que adaptará a uma das casas que desenha para a família Andrade em Lisboa, também não foi realizado, acabando por ser entregue a um outro arquitecto italiano, Luigi Manini, que, em Sintra, desenvolve "un piccolo e interessante saggio di architettura castellana del nord Italia filtrata attraverso il romantico del pittoresco di derivazione inglese, attento all'integrazione dell' architettura nel pa-

${ }^{26}$ Ver desenhos in "Fondo Locati", Dipartimento di Ingegneria edile e del Territorio della Facoltà di Ingegneria dell'Università di Pavia (ALUPv); e S. Locati, Torre di San Vicente presso Belem, All' on. Società Esecutori di Pie Disposizioni in Siena 1893, Milano, Stabilim, Tipo Litografico Galileo, 1896, p. IX. Locati, por comparação com o Mosteiro dos Jerónimos, admite a participação, no projecto da Torre de Belém, do arquitecto Botaca, ou Potassi, que, segundo ele, "non sarebbe a meravigliarsi che fosse italiano, perchè era l'epoca in cui i nostri artisti venivano chiamati dappertutto: in Inghilterra in Francia, [...] in Spagna e in Portogallo". A propósito cita ainda o episódio do Convento de Mafra, em cujo concurso participam Juvarra, Canevari e Ludovice, que vence, ainda que, segundo Locati, "il disegno del nostro Juvarra fosse il migliore”, ib., p. XIV.

${ }^{27} \mathrm{Ib}$.

${ }^{28}$ Ver S. Locati, Sebastiano Gius. Locati, architetto: progetti costruzioni rilievi, tav. 93-95. 
esaggio e allo sfruttamento delle potenzialità del sito" ${ }^{29}$. Luigi Manini (1848-1936) ${ }^{30}$ foi arquitecto-cenógrafo no Teatro de São Carlos, tendo também desenvolvido qualificados projectos de arquitectura como o Palácio do Buçaco (1888-1907) e, em Sintra, os chalés Biester (1890-1891), do Relógio e Sassetti (1890), e, ainda, a Quinta da Regaleira (1898-1912).

\section{Casas para a Família ANDRAde em Lisboa}

Serão as casas para a Família Andrade em terrenos localizados numa das encostas da Avenida da Liberdade (Torel, junto ao antigo campo de Sant'Ana) o principal foco da actividade de Sebastiano Locati em Portugal. Após uma breve estadia em Lisboa em 1891, Locati regressa a Itália para, segundo o próprio, "farne gli sviluppi e sceglierne le maestranze, volendo i proprietari che le loro costruzioni fossero fatte in tutto all'italiana" ${ }^{\prime \prime}$.

A villa construída para Júlio de Andrade (1838-1906) 32 implanta-se no centro de um amplo lote de cerca de $2500 \mathrm{~m}^{2}$, sendo a composição da planta quadrada, com 20 metros de lado, seguindo os esquemas das ville clássicas com pátio central e evocando, segundo Locati, o "uso antico Iberico [di] un

${ }^{29}$ G. Piccarolo, "Villa e Villino, il tema dell'abitazione borghese nell'Opera di Luigi Manini”, G. Piccarolo; G. Ricci (coord.), Luigi Manini (1848-1936) architetto e scenografo, pittore e fotografo, Cinisello Balsamo, Silvana, 2007, p. 100 [catálogo].

${ }^{30}$ Estuda na Accademia di Brera e trabalha como cenógrafo no Teatro Civico di Crema e no Scala de Milão. Em 1879, transfere-se para Lisboa, indicado por Carlo Ferrario (em sua substituição) para trabalhar como cenógrafo no Teatro de São Carlos. Em Portugal, realiza diversas cenografias e pinturas decorativas de teatros, além de importantes projectos de arquitectura. Em 1913 regressa a Itália onde termina a sua carreira profissional. Ver Luigi Manini (1848-1936) architetto e scenografo, pittore e fotografo, passim.

${ }^{31}$ Ver S. Locati, Sebastiano Gius. Locati, architetto: progetti costruzioni rilievi, p. 29.

32 Irmão de Alfredo de Andrade, foi director do Banco de Portugal e do Banco Lisboa \& Açores e fundou a Sociedade Protectora dos Animais, onde desempenhou cargos de grande relevo. 
cortile centrale a loggiati sovrapposti"33, onde é introduzida a estátua de Phyrne de Francesco Barzaghi (1839-1892) no centro do peristilo.

Sobre a solução construtiva adoptada, Locati observa que em Lisboa se usava ainda o sistema de alvenaria em gaiola de madeira e pedra como solução anti-sísmica, sujeita, porém, a problemas de degradação na madeira. Propõe, em alternativa, o uso de perfis de ferro pré-fabricado em duplo "T" (ou "H") que manda vir da Alemanha. Contudo, anos mais tarde, Locati viria a referir que, se tivesse usado o betão armado que "ora rivoluziona il mondo delle costruzioni [...] quanto lavoro [...] io avrei allora potuto risparmiare!" ${ }^{34}$.

A villa Bastos $^{35}$, de menores dimensões, apresenta uma solução volumétrica mais articulada, em "L", com o átrio octogonal no ângulo de entrada, rematado superiormente por uma varanda-belvedere. O programa de recepção define-se a partir de uma sequência de três salóes, solução também presente na casa Júlio de Andrade, mas que aqui atinge maior expressão pela introdução de vidros nas divisórias entre as salas, acentuando cenograficamente a transparência e fluidez espacial: "tre sale principali le quali all'occorrenza potevano formare - con bella visuale - un salone unico grazie alle colone che le dividevano" ${ }^{36}$. Estes espaços são concebidos como peças de recepção e representação, enfatizados por um programa decorativo em que participa um artista de Milão, Lodovico Pogliaghi (1857-1950) ${ }^{37}$.

No que respeita ao tratamento exterior, as casas apresentam um repertório decorativo semelhante - neo-renascen-

${ }^{33}$ S. Locati, Sebastiano Gius. Locati, architetto: progetti costruzioni rilievi.

${ }^{34} \mathrm{Ib}$., pp. 27-28.

${ }^{35}$ Ver requerimento para construção, acompanhado do projecto (04-09-1891) para Guilhermina d'Andrade Bastos, irmã de Alfredo de Andrade, e Júlio d'Oliveira Bastos, AHCML, Obra 25087 (Rua Júlio de Andrade 3-3a).

${ }^{36}$ S. Locati, Sebastiano Gius. Locati, architetto: progetti costruzioni rilievi, p. 28.

${ }^{37}$ Carta de A. Andrade a L. Pogliaghi, de 26-08-1904, APFA. 
tista - sendo o investimento no alçado poente, sublinhado por dispositivos como logge, bow-window, belvedere e pergola que potenciam a relação com a paisagem e caracterizam fortemente a imagem urbana das casas, remetendo para as ville áulicas no cimo da colina.

Sebastiano Locati vai ainda construir mais duas casas no Torel, de menores dimensões, para Manuel de Castro Guimarães (1858-1927), cunhado de Alfredo de Andrade ${ }^{38}$. Uma destas, o villino situado na Rua Júlio de Andrade n. ${ }^{\circ}$ 6 , apresenta planta quadrangular e volumetria compacta, de composição simétrica e tripartida, com tratamento exterior de elegante desenho neo-renascentista marcado pelo elemento central saliente na fachada principal e rematado superiormente por uma cúpula com lanternim. Por seu lado, no outro villino, situado na Rua Júlio de Andrade n. ${ }^{\text {os }} 2-4^{39}$, detectam-se semelhanças com o projecto de Locati para o Villino Sassetti, designadamente a combinação de referências do medievalismo lombardo - volumetria compacta, torre e beirados salientes - com alguns elementos de derivação neo-renascentista nos vãos e nos frisos.

Por fim, apresenta-se um último projecto de 1898-1899, de duas casas de rendimento para Júlio de Andrade localizadas na Avenida António Augusto de Aguiar, projectadas por Nicola Bigaglia (1841?-1908) ${ }^{40}$. Este foi um importante arquitecto em Portugal, quer pela quantidade quer pela qualidade das suas obras. Quando projectou as casas para Júlio de Andrade,

${ }^{38}$ Francisco de Sousa Viterbo, cit., vol. 3, p. 351.

${ }^{39}$ Ver AHCML, Obra 31311 (R. Júlio de Andrade, 2-4).

${ }^{40}$ Revela uma sólida formação nos domínios da pintura, do desenho e da arquitectura, destacando-se também no ensino. Executou projectos em diversos campos, desde a arquitectura religiosa e funerária aos equipamentos públicos, jardins, restauro e decoração dos interiores. A sua actividade concentra-se predominantemente em Lisboa, onde se evidenciam os palácios Mayer e Lambertini (ambos prémio Valmor). Noutros locais, citam-se o chalé do Cão no Buçaco, a Quinta de Santiago em Leça da Palmeira e o chalé da Condessa d'Edla na Parede. Ver M. Calado, A cultura arquitectónica em Portugal. 1880-1920, tradição e inovação, Tese de doutoramento apresentada à FAUTL, 2003, vol. 2, p. 67. 
Bigaglia já tinha assinado projectos como o Teatro Avenida, em Lisboa (inaugurado em 1888), o Teatro Luísa Todi, em Setúbal (1894) e o Chalé do Cão, no Buçaco (1898). É possível que tenha sido Alfredo de Andrade a trazer também Nicola Bigaglia para Portugal ${ }^{41}$, a julgar por um pedido de Francisco Benevides da Fonseca ${ }^{42}$ para indicação de professores italianos para ensinar desenho nas novas Escolas Industriais.

$\mathrm{O}$ terreno apresenta uma área de aproximadamente $600 \mathrm{~m}^{2}$ sendo as casas implantadas com a frente ligeiramente recuada relativamente à Avenida ${ }^{43}$. Os alçados sobressaem pela elegância, harmonia e sobriedade, resultado da introdução de princípios compositivos rigorosos e de um só código estilístico - neo-renascentista -, denominadores comuns das casas construídas por arquitectos italianos para a família Andrade em Lisboa nos finais do século XIX.

\section{Villino de Font'Alva no Alentejo}

Como vimos, Alfredo de Andrade (1839-1915) ${ }^{44}$ é um importante elo nas relaçóes entre Itália e Portugal na segunda metade do século XIX. Formado artisticamente em Itália -

${ }^{41} \mathrm{O}$ facto de Bigaglia ser proveniente de Veneza leva-nos a suspeitar que o seu nome tenha sido sugerido, de novo, por Camillo Boito, que ali havia estudado e trabalhado, tendo-se mantido sempre ligado ao ambiente artístico veneziano. Ver T. Ferreira, cit., p. 293.

${ }^{42}$ Carta de F. Benevides da Fonseca a A. Andrade, 08-10-1887, APFA.

${ }^{43}$ Não foi possível saber quem habitou e quem comprou posteriormente as casas, visto que foram demolidas durante o século XX. Ver AHCML, Obra 25962, demolida, com registo 3294 (Av. António Augusto de Aguiar, n. ${ }^{\text {os } 34-36) .}$

${ }^{44}$ Parte para Itália, com quinze anos, para estudar a actividade comercial paterna e para não mais voltar, definitivamente. Andrade estuda na Accademia Ligustica de Génova e desenvolve uma actividade multifacetada, entre Itália e Portugal - como pintor, professor, arqueólogo e arquitecto -, tendo coordenado mais de trezentos restauros, dispersos pelo Norte de Itália. É também nomeado para inúmeros cargos públicos no âmbito da instrução artística e da salvaguarda do património artístico e monumental. Em 1912 é-lhe concedida a nacionalidade italiana. Ver, entre outros, M. G. Cerri; D. Biancolini; L. Pittarello (coord.), Alfredo d'Andrade. Tutela e Restauro, Firenze, Vallecchi, 1981; L. V. Costa, cit., ; T. Ferreira, cit. 
país onde desenvolve predominantemente a sua actividade profissional, ocupando cargos públicos dirigentes no âmbito do ensino artístico, bem como da salvaguarda e restauro do património artístico e monumental - mantém uma relação constante com Portugal, onde viria a construir uma casa, o Villino de Font'Alva no Alentejo, testemunho autobiográfico voluntariamente deixado no país de origem.

Este villino referencia-se a modelos italianos, cruzando elementos de arquitectura neo-renascentista e castelá, sendo os operários e sistemas construtivos importados do restauro do Castello di Pavone, a sua residência em Itália ${ }^{45}$. O villino remata, a poente, um eixo que passa pelo complexo murado do pátio rústico (corte rústica) e por uma avenida de 200 ciprestes, "à moda das da Itália nas ville romanas e toscanas" 46 . Enquadrando-se na produção ecléctica de fim de século, Andrade projecta a obra total, marcada pelo seu quadro de referências e pela experiência profissional em Itália, mas também por uma qualidade construtiva e uma atenção ao detalhe que caracterizam toda a sua carreira profissional.

Deste modo, importa enquadrar criticamente estes processos na produção ecléctica de final de Oitocentos, numa época em que se intensifica a circulação de artistas e modelos, superando visões historiográficas preconceituosas ou redutoras relativas ao século XIX ${ }^{47}$, em favor de uma visão plural e culturalmente complexa. Por fim, sublinha-se que a reconstituição documentada de projectos de arquitectos italianos em Portugal, na maioria desconhecidos ou pouco estudados, contribui para o enriquecimento do conhecimento sobre a cultura arquitectónica dos séculos XIX e XX.

${ }^{45}$ Ver R. Andrade, Font'Alva. Alfredo D'Andrade. Uma grande empresa agrícola. Obra de um grande artista, Lisboa, ed. autor, 1948; T. Ferreira, cit., pp. 299-362.

${ }^{46} I b .$, p. 80 , n. 2.

${ }^{47}$ Vários autores assinalaram a depreciação da arquitectura do século XIX pela historiografia moderna, que, na enfatização da sua poética, acabou por obscurecer as suas próprias origens. Ver I. Solà-Morales, prólogo a P. Collins, Los ideales de la arquitectura moderna; su evolución (1750-1950), Barcelona, Gustavo Gili, [1965] 1981, p. 2. 


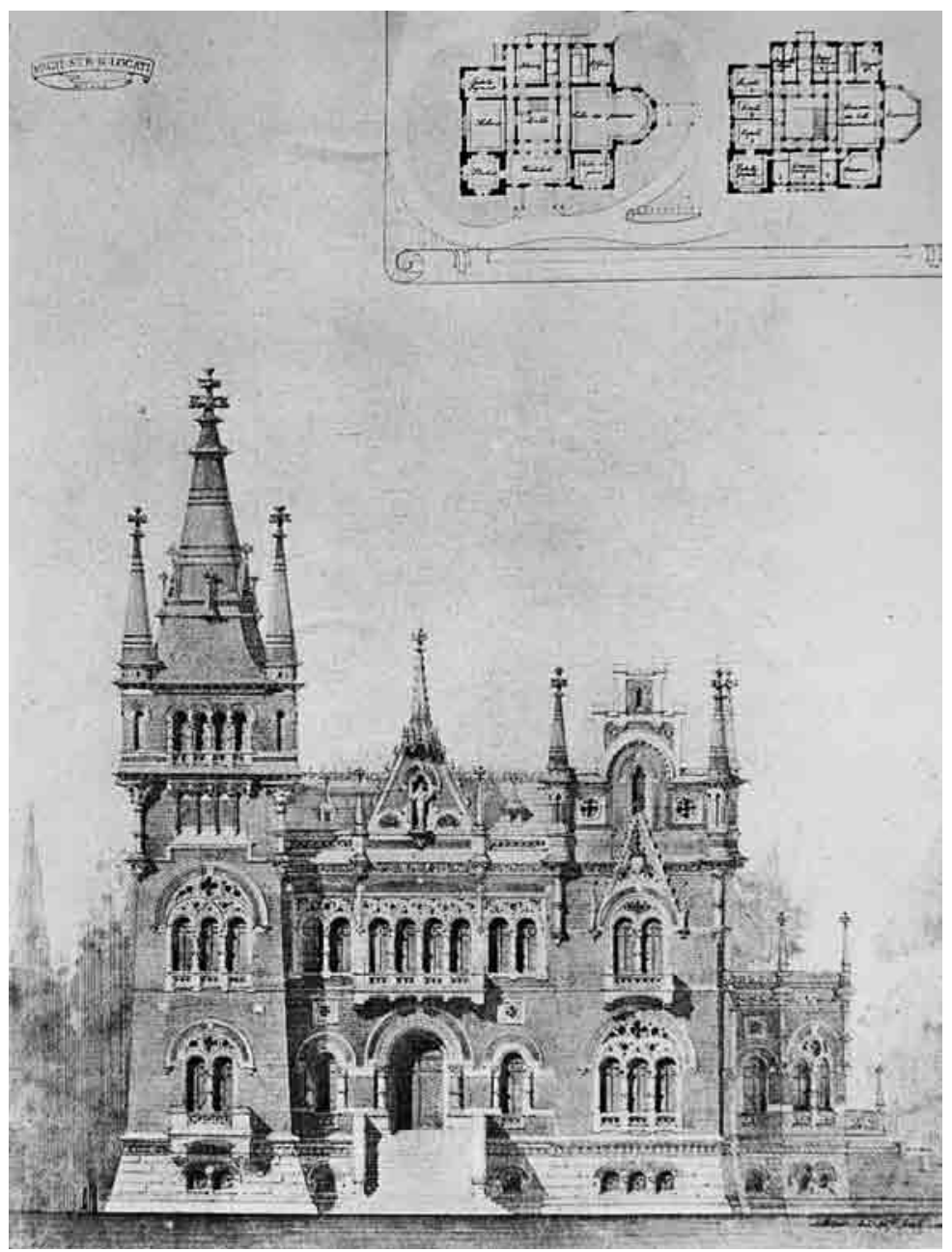

Fig. 1 Sebastiano Locati, Villino D’Almeida no Estoril, 1891 (Arquivo Locati, Universidade de Pavia). 


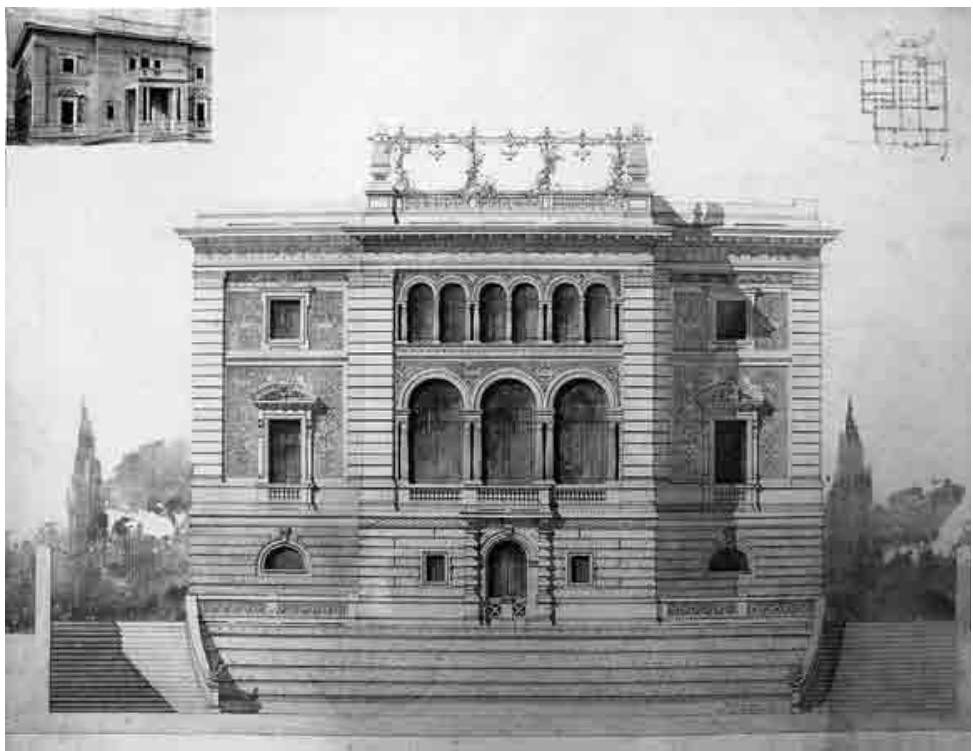

Fig. 2 Sebastiano Locati, Villa Giulio D’Andrade, Lisboa, 1892 (Arquivo Locati, Universidade de Pavia).

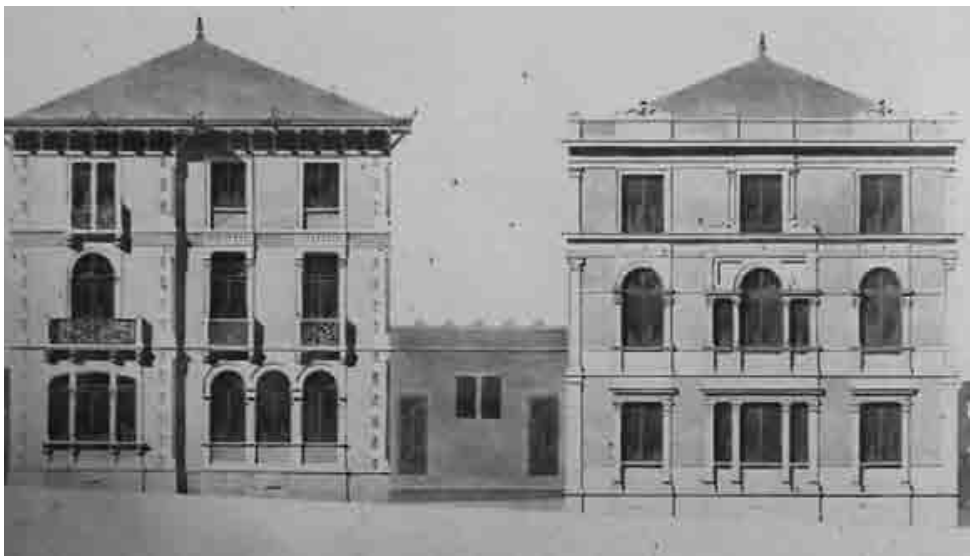

Fig. 3 Nicola Bigaglia, Casas na Avenida António Augusto de Aguiar, Lisboa, 1899 (Arquivo Privado Família Andrade). 


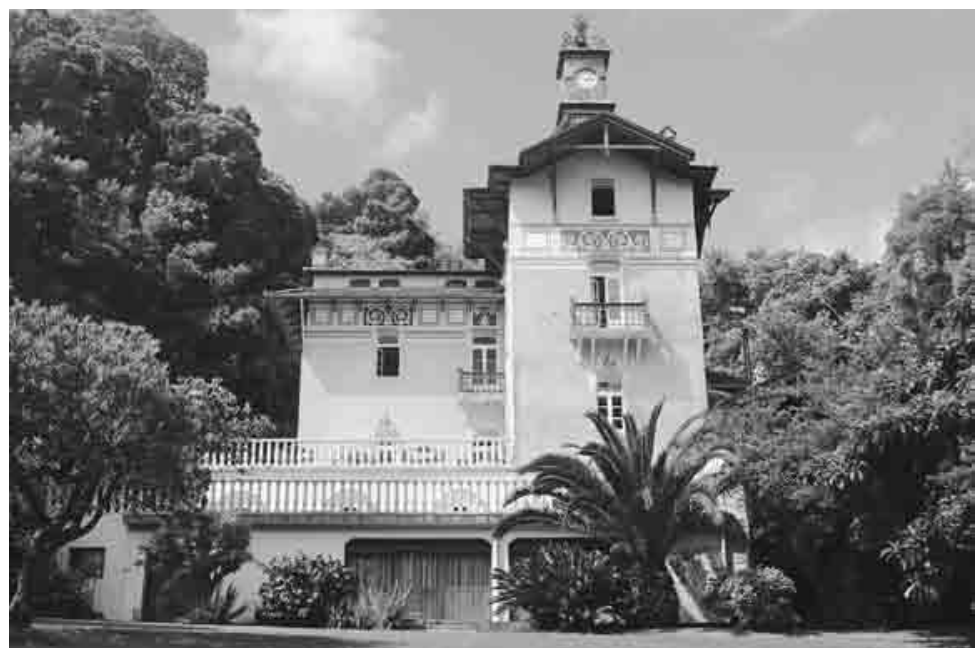

Fig. 4 Luigi Manini, Chalé do Relógio ou Casa del Giardiniere Biester, Sintra, 1891.

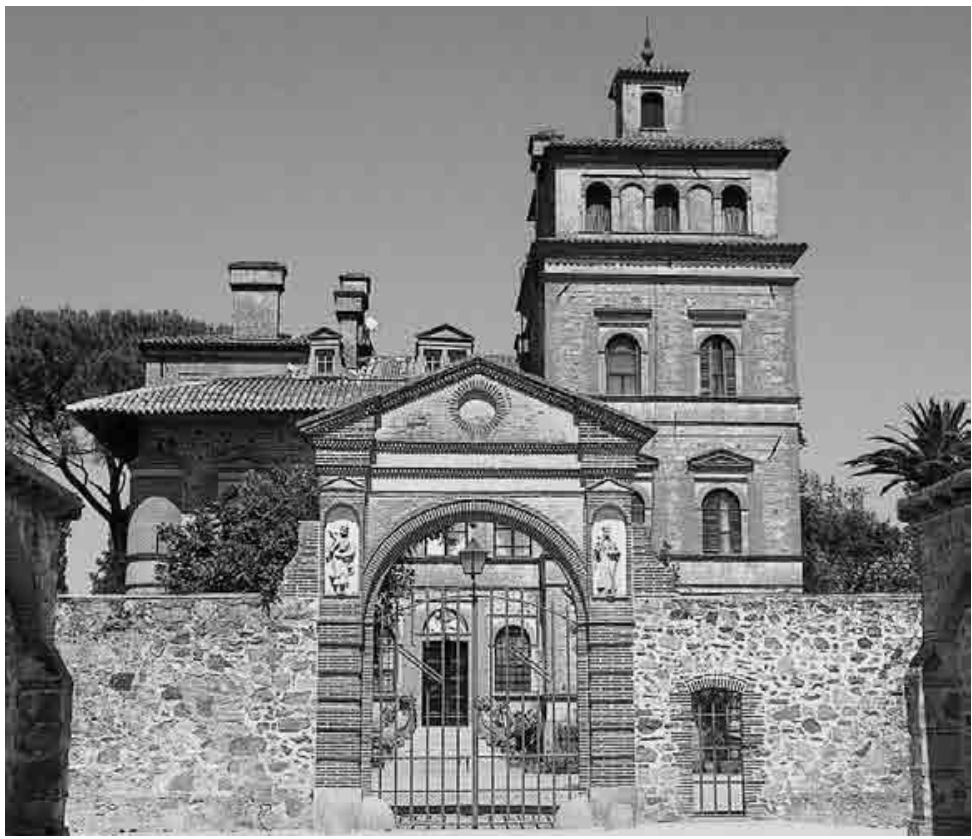

Fig. 5 Alfredo de Andrade, Villino de Font'Alva, Elvas, 1894-1895. 